\title{
Quantitative analysis of calf mortality in Great Britain
}

\author{
Robert M. Hyde, ${ }^{1 *} \odot$ Martin J. Green, ${ }^{1} \odot$ Virginia E. Sherwin, ${ }^{1}$ Chris Hudson, ${ }^{1} \odot$ Jenny Gibbons, ${ }^{2} \odot$ \\ Tom Forshaw, ${ }^{2}$ Mary Vickers, ${ }^{2}$ and Peter M. Down ${ }^{1}$ (1) \\ ${ }^{1}$ School of Veterinary Medicine and Science, University of Nottingham, Sutton Bonington Campus, Leicestershire, United Kingdom LE12 5RD \\ ${ }^{2}$ Agriculture and Horticulture Development Board, Stoneleigh, Kenilworth, United Kingdom, CV8 2TL
}

\begin{abstract}
National bodies in Great Britain (GB) have expressed concern over young stock health and welfare and identified calf survival as a priority; however, no national data have been available to quantify mortality rates. The aim of this study was to quantify the temporal incidence rate, distributional features, and factors affecting variation in mortality rates in calves in GB since 2011. The purpose was to provide information to national stakeholder groups to inform resource allocation both for knowledge exchange and future research. Cattle birth and death registrations from the national British Cattle Movement Service were analyzed to determine rates of both slaughter and on-farm mortality. The number of births and deaths registered between 2011 and 2018 within GB were 21.2 and 21.6 million, respectively. Of the 3.3 million on-farm deaths, 1.8 million occurred before 24 mo of age $(54 \%)$ and $818,845(25 \%)$ happened within the first 3 mo of age. The on-farm mortality rate was $3.87 \%$ by 3 mo of age, remained relatively stable over time, and was higher for male calves $(4.32 \%)$ than female calves $(3.45 \%)$. Dairy calves experience higher on farm mortality rates than nondairy (beef) calves in the first 3 mo of life, with 6.00 and $2.86 \%$ mortality rates, respectively. The 0 - to 3 -mo death rate at slaughterhouse for male dairy calves has increased from $17.40 \%$ in 2011 to $26.16 \%$ in 2018 , and has remained low $(<0.5 \%)$ for female dairy calves and beef calves of both sexes. Multivariate adaptive regression spline models were able to explain a large degree of the variation in mortality rates (coefficient of determination $=96 \%$ ). Mean monthly environmental temperature and month of birth appeared to play an important role in neonatal on-farm mortality rates, with increased temperatures significantly reducing mortality rates. Taking the optimal month of birth and
\end{abstract}

Received August 2, 2019.

Accepted November 16, 2019.

*Corresponding author: Robert.hyde1@nottingham.ac.uk environmental temperature as indicators of the best possible environmental conditions, maintaining these conditions throughout the year would be expected to result in a reduction in annual 0- to 3-mo mortality of 37,571 deaths per year, with an estimated economic saving of around $£ 11.6$ million (USD $\$ 15.3$ million) per annum. National cattle registers have great potential for monitoring trends in calf mortality and can provide valuable insights to the cattle industry. Environmental conditions play a significant role in calf mortality rates and further research is needed to explore how to optimize conditions to reduce calf mortality rates in GB. Key words: calf mortality, monitoring, national data

\section{INTRODUCTION}

Neonatal mortality (defined as $1 \mathrm{~d}$ of age to weaning; Compton et al., 2017) represents a significant loss to the British cattle industry. Calf management is critical in rearing productive dairy cows (Hultgren and Svensson, 2009), and represents a significant economic outlay, accounting for around $20 \%$ of total dairy farm expenditure (Gabler et al., 2000) with costs in Great Britain (GB) estimated at around $£ 1,819$ per animal (Boulton et al., 2017). A study following 1,097 calves from 19 farms in England suggest 15\% of liveborn dairy heifers die before reaching their first lactation (Brickell et al., 2009), with the cost of heifer mortality representing around $£ 139$ per animal when spread across surviving animals (Boulton et al., 2017). Effective calf management is also crucial for efficient beef production (Mõtus et al., 2017), which is a significant industry for the United Kingdom, being the third largest producer of beef in Europe (DEFRA, 2018).

Neonatal mortality not only represents an economic loss, but also delays genetic progress by providing fewer replacements for voluntary culling (Raboisson et al., 2013). Mortality has also been explored as a marker for farm welfare surveillance and has been suggested as an indicator of overall health on cattle farms (Ortiz-Pelaez et al., 2008; von Keyserlingk et al., 2009). The effective management of neonatal calves is essential for survival, 
welfare, and productivity (Renaud et al., 2018), and although mortality in calves is unlikely to be entirely eradicated, reducing it as much as possible should be a goal (Santman-Berends et al., 2014).

To prevent disease and reduce mortality, it is essential to understand the incidence, prevalence, distribution, and key factors that influence disease variability; this is the basis of epidemiology and is recognized as a first step in disease control (Dohoo et al., 2003). National bodies in GB have expressed concern over youngstock health and welfare, identifying calf survival as a priority (CHAWG, 2017, 2018b). However, currently no national data are being published and therefore the extent of the problem remains largely unknown. A clear understanding of patterns of calf mortality on a national scale would inform stakeholders of whether and where to allocate resources both for knowledge exchange and further research. Furthermore, quantification of risk between groups (e.g., beef or dairy calves, male or female calves, and specific times of year) would allow targeting of resources toward high-risk populations and time periods.

The use of national level data for epidemiological studies has been called for to help develop methods of reducing morbidity and mortality (Santman-Berends et al., 2014; Veldhuis et al., 2016), but rates of calf mortality in GB have not been evaluated nationally since 2007 (Gates, 2013). While keepers of bovine animals in GB must register births, deaths, and movements of their animals through the Cattle Tracing System, the data are not used to routinely report national incidence rates of calf mortality.

The aim of this study was to quantify the temporal incidence rate, distributional features, and factors affecting variation in mortality rates in calves in GB since 2011. The purpose was to provide information to national stakeholder groups to inform resource allocation for both for knowledge exchange and future research.

\section{MATERIALS AND METHODS}

Birth and death data from 2010 to 2019 were requested from British Cattle Movement Services (BCMS). Data were only available at county level and included the number of births for each county, country, breed, sex, month, and year as an aggregated figure. Death data were provided in a similar format; however, the data excluded county level information and contained the number of deaths for each age at death (mo), premises of death (i.e., on farm or slaughterhouse), country, sex, breed, month, and year. On-farm deaths included animals that died on farm, and slaughterhouse deaths included any animals that were transported to a slaughterhouse for slaughter. These data sets were combined to allow calculation of estimated mortality rates for defined groups.

Births and deaths (of any age) were filtered to be after 2010 and before 2019. The premises of death consisted of 5 categories; slaughterhouse, farm, market, hunt/knackers (colloquial terms for fallen stock removal enterprises), and other. The vast majority of deaths $(99.97 \%)$ were reported on-farm or at a slaughterhouse. Given that less than $0.03 \%$ of deaths were categorized as market, hunt/knackers, or other, it was decided to exclude these from the data set. Breeds were categorized as either dairy or nondairy (i.e., beef, including beef cross dairy) according to BCMS categories. A small proportion $(<0.05 \%)$ of animals were noncattle (i.e., bison, yak, and water buffalo) and were removed from the data set.

Cumulative mortality rates were calculated as a percentage of animals born in a specific month subsequently dying within a defined time period. For example, of 100 calves born in January, 2 calves dying in January at 0 to 1 mo of age, 2 dying in February at 1 to 2 mo of age, and 1 dying in March at 2 to 3 mo of age would result in a 0 - to 3 -mo mortality rate of $5 \%$. Country and county were excluded from analysis to avoid the potentially erroneous assumption of zero cross-border transport between birth and death (e.g., the assumption that calves that die in Scotland were also born in Scotland).

British cattle must be dual-tagged within $20 \mathrm{~d}$ of birth, and all births and deaths must legally be registered through BCMS. There is a requirement that deaths that occur before tagging also be recorded within the holding register, and inspectors visit a proportion of UK farms (at least 3\% of holdings annually) to validate identification and record-keeping protocols (UK Government, 2014). While it is unlikely that many stillborn (0- to 24-h mortality) calves will be included within registered deaths, the current stillborn rate in GB continues to be uncertain.

Descriptive and statistical analyses were conducted in $\mathrm{R}$ ( $\mathrm{R}$ Core Team, 2018). On-farm mortality was treated separately to slaughterhouse deaths, and descriptive graphical analysis was conducted by breed, sex, age, and month. Linear regression methods were employed to provide insight into potentially influential factors associated with calf mortality at 0 to $3 \mathrm{mo}$ of age. These factors included the breed, sex, month of birth, and Met Office meteorological data (mean, minimum, and maximum monthly temperatures across the United Kingdom). To explore interactions between variables and nonlinearities within the data, multivariate adaptive regression spline models (Friedman, 1991) were employed using the earth (Milborrow, 2019) and 
caret (Kuhn, 2018) $R$ packages. Interactions up to order 3 were tested and the maximum number of terms available to the model was explored and optimized using a dense grid of values between 2 and 25 in increments of 1 . Ten-fold cross-validation repeated 10 times was used to identify the optimal value of these tuning parameters; optimization was based on minimizing model mean absolute error (MAE). Final model covariates were therefore selected based on minimizing the crossvalidation model MAE; covariate selection is an integral part of the multivariate adaptive regression splines (MARS) procedure (Friedman, 1991). An evaluation of model fit and the extent of over-fitting was assessed by a comparison of MAE and coefficient of determination $\left(\mathbf{R}^{2}\right)$ computed from the final model based on the full data set (internal fit) and computed from 10-fold cross validation (cv-fit). Residuals were examined to ensure model fit by examining fitted values against residuals to ensure the model was not over- or underpredicting mortality rates, particularly at the extremities of fitted values.

To estimate the effect of optimizing environmental conditions on calf mortality, covariates in the final model were used to predict how mortality might change with different environmental temperatures or different months of birth.

\section{RESULTS}

The cattle population in the United Kingdom is around 9.6 million (UK Government, 2018). The num- ber of births and deaths registered between 2011 and 2018 across GB were 21.2 and 21.6 million respectively, of which 18.3 million and 3.3 million deaths were at slaughterhouse and on farm, respectively. Of the total on-farm deaths, 1.8 million occurred before 24 mo of age (54\%, Figure 1), and 819,703 (25\%) happened within the first $3 \mathrm{mo}$ of age. Of the 818,845 dairy cattle that died on farm before 24 mo of age, 409,612 (50\%) died within the first 3 mo of age, and of the 956,293 nondairy cattle that died on farm before 24 mo of age, 410,091 (43\%) died within 3 mo of age. Of the 18.3 million deaths that were recorded at slaughterhouses, $644,848(3.5 \%)$ were before 3 mo of age. The 0- to 3 -mo death rate at slaughterhouses (and excluding any onfarm mortality) was $0.49,0.21$, and $0.34 \%$ for dairy females, nondairy females, and nondairy males, respectively, and was $19.94 \%$ for dairy males.

The on-farm (excluding any slaughterhouse deaths) mortality rate was $3.87 \%$ by 3 mo of age, and was higher for male than female calves, with male calves experiencing a mortality rate of $4.32 \%$ compared with $3.45 \%$ for female calves. Dairy calves experienced higher mortality rates than nondairy calves within 3 mo of age, with 6.00 and $2.86 \%$ mortality rates, respectively. Male dairy calves had the highest on-farm mortality rate within 3 mo of $7.37 \%$ compared with a mortality rate of $4.96 \%$ for female dairy calves. Female nondairy calves had the lowest mortality rate within 3 mo of $2.61 \%$ compared with a mortality rate of $3.10 \%$ for male nondairy calves.

On-farm mortality rates remained relatively stable over time (Figure 2). Male dairy calves appeared to

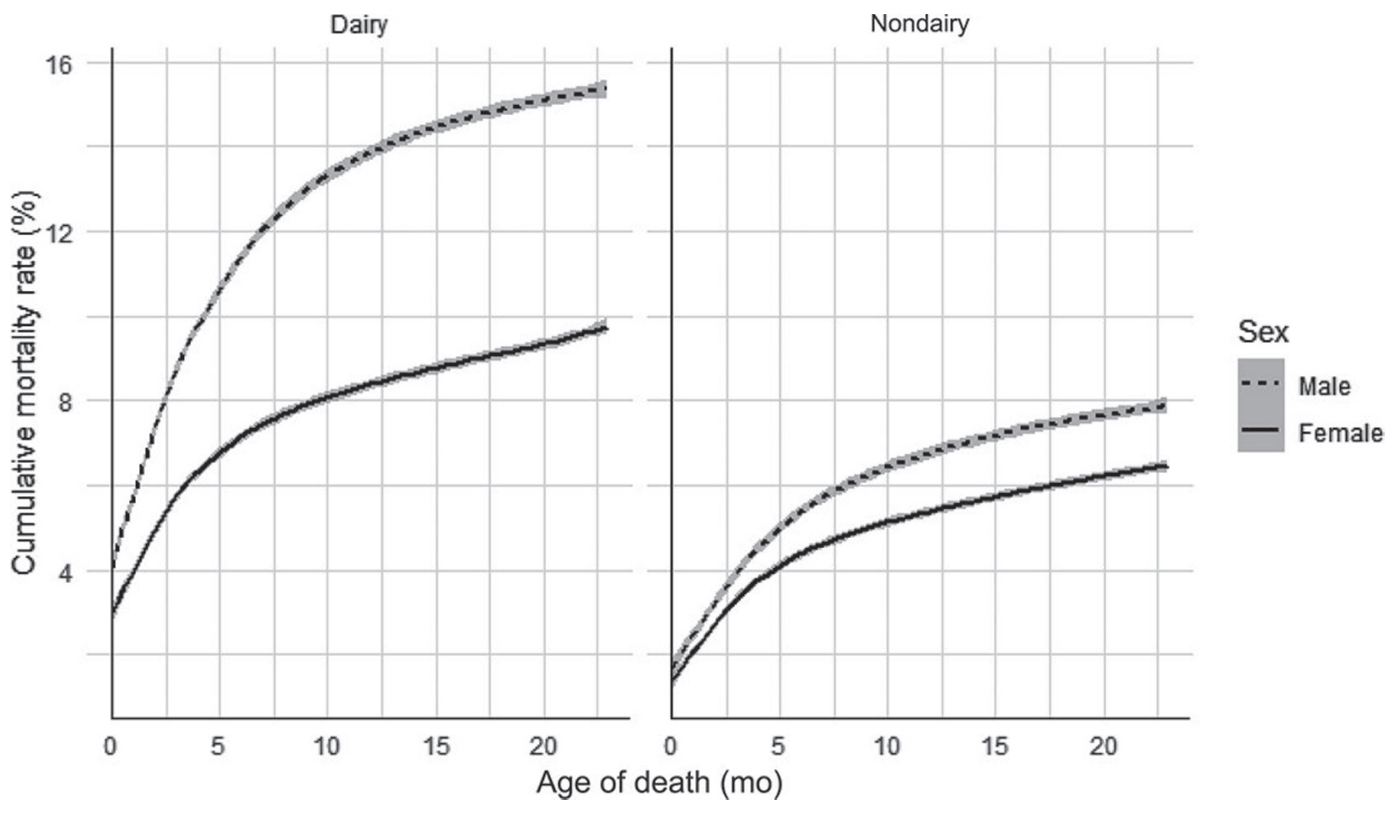

Figure 1. Cumulative on-farm mortality rates by age, sex, and breed type. Gray shading indicates $95 \%$ CI. 


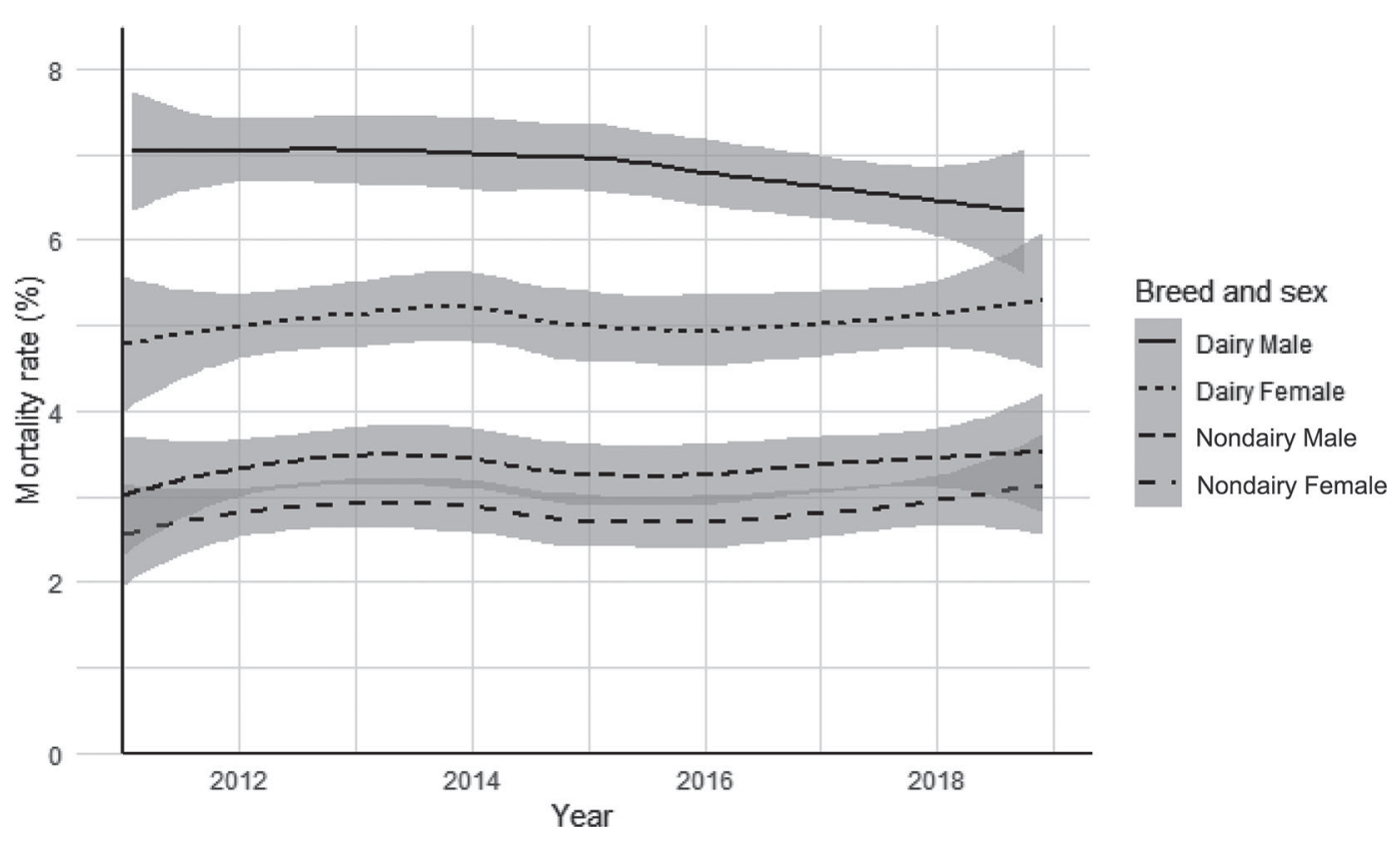

Figure 2. On-farm mortality rate for 0 to 3 mo of age (\%) by year, breed type, and sex from 2011 to 2018 . Gray shading indicates $95 \%$ CI.

be the only category of animal being routinely sent for slaughter at 0 to $3 \mathrm{mo}$ of age, and this appeared to show an upward trend over time, from $17.40 \%$ in 2011 to $26.16 \%$ in 2018 (Figure 3 ). There appeared to be a strong seasonal component to 0- to 3-mo on-farm mortality rates across both breed types and sexes (Figure 4 ), with dairy calves having a lower 0- to 3-mo mortality rate during summer, with a rate of $6.61,6.11,4.79$, and $6.74 \%$ for dairy calves born during winter, spring, summer, and autumn, respectively. Similarly, nondairy calves had a lower mortality rate when born during summer and also had a lower rate during spring, with the highest rate being autumn (winter: $2.88 \%$; spring: 2.56\%; summer: $2.56 \%$; and autumn: $3.98 \%$ ).

Results of the final MARS model are provided in Table 1. Both sex and breed type were associated with differences in mortality rate, with an increased rate for male calves and decreased rate for beef calves. Month of birth had an effect on mortality rate, and the mortality rate in the first 3 mo of life increased for calves born in December by $+1.1 \%$. While mortality rate was reduced for calves born during February $(-1.4 \%)$, there was an interaction between breed type and month of birth (February $\times$ nondairy) of $+1.0 \%$, resulting in a predicted mortality rate change of $-0.4 \%$ for nondairy calves born in February (as opposed to dairy calves born in February, which had a predicted rate of $-1.4 \%$ ). Similarly, dairy calves born in November had a mortality rate change of $+0.3 \%$, compared with $+0.9 \%$ for nondairy calves (the interaction effect of November $\times$ nondairy $=+0.6 \%)$. Interactions were observed between month and breed type for February, March, October, and November, and interactions between month and sex for January and August indicating that these subsets of animals at these specific times had different predicted risks of mortality.

The MARS models identified a hinge point (hp) within the mean monthly temperature variable at $4.8^{\circ} \mathrm{C}$, and at $9.6^{\circ} \mathrm{C}$ where an interaction effect with nondairy (beef) calves was included. This indicated that reduced mean monthly temperatures were associated with increased calf mortality regardless of month, and this association was slightly stronger below $4.8^{\circ} \mathrm{C}$. An interaction term for nondairy breed type and temperature was present: nondairy $\times \mathrm{hp}$ (mean temperature $-9.6^{\circ} \mathrm{C}$ ). This interaction term coefficient indicated a change in mortality rate for nondairy calves (denoted by nondairy $\times \mathrm{hp}$ ) for each $1^{\circ} \mathrm{C}$ above $9.6^{\circ} \mathrm{C}$ [as denoted by (mean temperature $-9.6^{\circ} \mathrm{C}$ )] of $-0.2 \%$, effectively neutralizing the $0.2 \%$ decrease in mortality above $4.8 \%$ suggested by the term $h p\left(4.8^{\circ} \mathrm{C}\right.$ - mean temperature). In short, this indicated that the mortality of nondairy calves increased by $0.2 \%$ for every $1^{\circ} \mathrm{C}$ decrease in temperature, but that this effect was limited to below $9.6^{\circ} \mathrm{C}$ only, and temperature had a minimal effect on the mortality rate of nondairy calves above this point.

Analysis of model fit showed an $\mathrm{R}^{2}$ value of $95.77 \%$, root mean square error of 0.44 , and MAE of 0.34 when using 10-fold cross validation, and an $R^{2}$ value of $96.24 \%$, root mean square error of 0.40 , and MAE 
of 0.31 when using internal fit, indicating no signs of model overfitting. Optimal model parameters were a degree of 2 interactions, and the number of terms for inclusion (nprune) set at 16.

To examine the effect of environmental conditions on calf mortality, the final model was used to predict mortality given optimal month and environmental temperature. Calves born in February were shown to have the lowest mortality rate independent of temperature, and increased mean monthly environmental temperature was shown to decrease mortality rates at 0 to 3 mo of age independent of month (the maximum monthly mean temperature recorded was $17.3^{\circ} \mathrm{C}$ ).

Predictions of mortality were made by assuming all calves were born in February and with the environmental temperature set constantly at $17.3^{\circ} \mathrm{C}$. This resulted in an estimated total reduction of 300,570 deaths at 0 to 3 mo of age over the period 2011 to 2018 , equating to a mean reduction of 37,571 fewer deaths per year.

\section{DISCUSSION}

This research represents one of the largest calf mortality data sets ever reported and suggests minimal change in GB calf mortality rates between 2011 and 2018. The results indicate that environmental temperature, time of year, sex, and breed type are strong predictors of mortality rate, and account for around $96 \%$ of the total variation in on-farm mortality. Importantly, it appears that relatively low mortality rates are achievable at specific times of year, in certain groups of animals, and in relatively warm temperatures. For example, in the lowest risk groups for both dairy and nondairy breed types (female calves born in February) a mortality rate of $<2 \%$ would be expected at temperatures of $17.3^{\circ} \mathrm{C}$ (the maximum monthly temperature recorded). If the environmental conditions provided for these groups of animals could be identified and replicated through improvements in housing management, a reasonable national target for the British cattle industry could be to reduce overall 0 - to 3 -mo calf mortality to $<2 \%$. To achieve this, further research into and understanding of these specific environmental conditions is required; these areas are discussed below.

The effect of environmental temperature and month of birth appear to play a significant role in neonatal mortality rates. Reduction in mortality during summer has been previously reported in both dairy (Lombard et al., 2007; Raboisson et al., 2013) and beef calves (Mõtus et al., 2017), and colder temperatures have been suggested as an important factor in mortality rates, with temperatures of $\geq 10^{\circ} \mathrm{C}$ being associated with lower mortality (Pannwitz, 2015). Colder weather may also have a negative effect on calf vigor, which may subsequently affect the transfer of passive immunity (Olson et al., 1980; Robison et al., 1988), an essential component in reducing morbidity and mortality (Godden, 2008; Cuttance et al., 2018). Increased infection

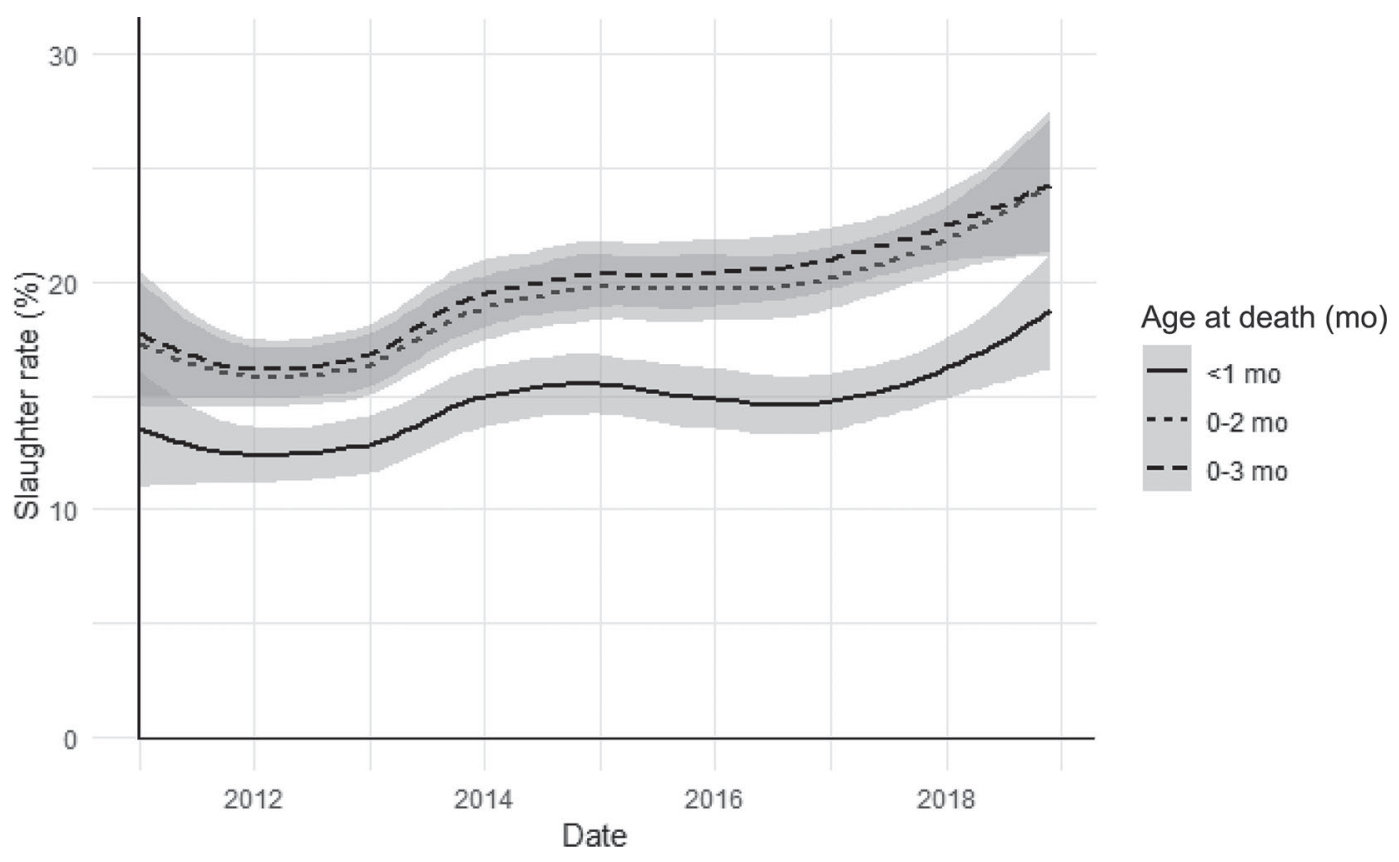

Figure 3. Slaughter rate over time of dairy bull calves for $<1,0$ to 2 , and 0 to 3 mo of age by date. Gray shading indicates $95 \%$ CI. 


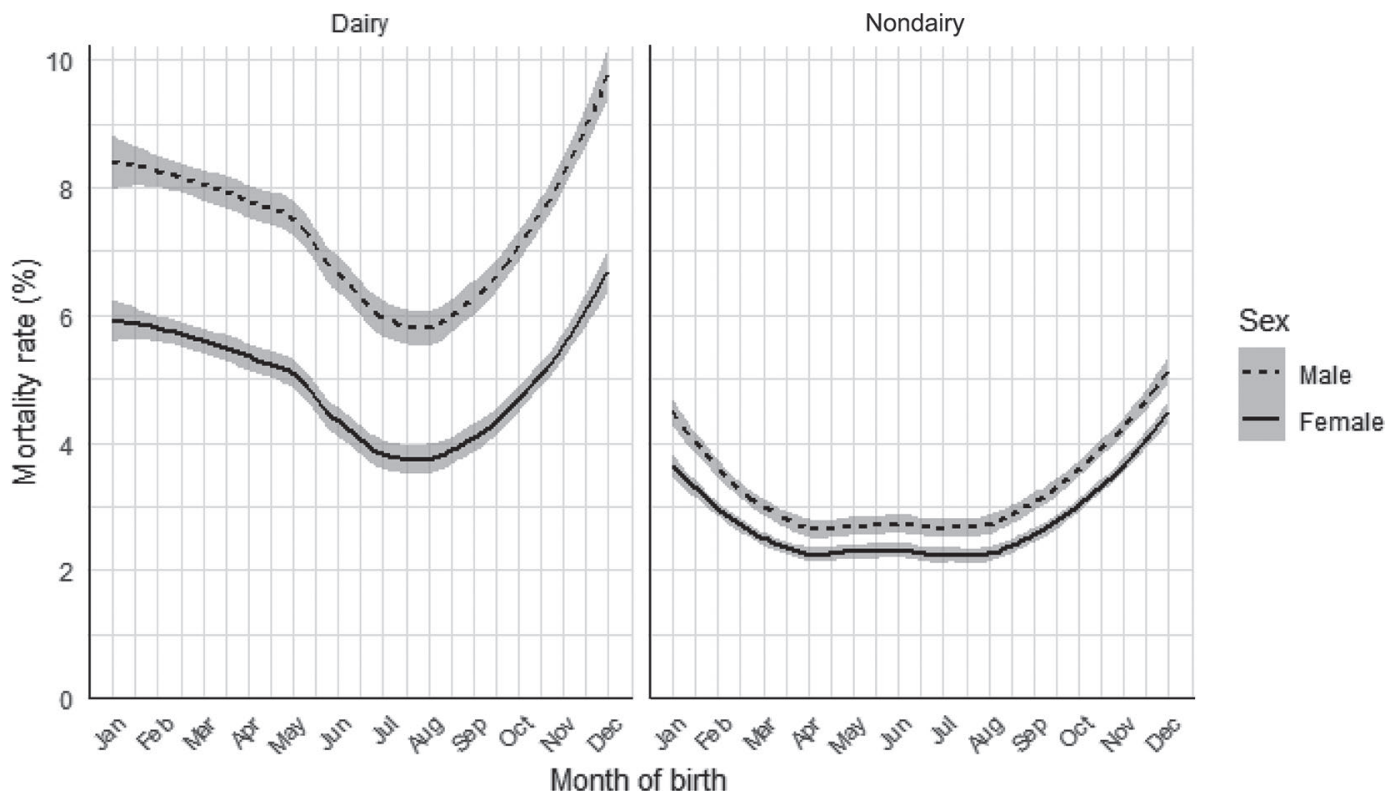

Figure 4. Seasonal patterns in on-farm 0- to 3-mo mortality rates by month of birth, breed type, and sex. Gray shading indicates $95 \%$ CI.

pressure during housing through winter may also have an effect, which might subsequently increases the risk of morbidity and mortality (Raboisson et al., 2013). The large effects of month and temperature suggest a substantial environmental component to the risk of mortality; if calf housing was able to replicate optimal environmental conditions all year round, major reductions in mortality could result. The potential mean annual reduction in mortality of 37,571 fewer deaths identified in this study as attributable to suboptimal environmental conditions represents a potential economic saving of around $£ 11.6$ million per year when

Table 1. Results from multivariate adaptive regression splines model; hp denotes hinge point

\begin{tabular}{lc}
\hline Variable & Coefficient \\
\hline Intercept & 6.0 \\
Breed type (nondairy) & -2.7 \\
Sex (male) & 2.4 \\
hp (mean temperature $\left.-4.8^{\circ} \mathrm{C}\right)$ & -0.2 \\
hp $\left(4.8^{\circ} \mathrm{C}-\right.$ mean temperature) & 0.2 \\
Sex (male) $\times$ breed type (nondairy) & -1.9 \\
Month (Mar) $\times$ breed type (nondairy) & -1.2 \\
Month (Feb) & -1.4 \\
Breed type (nondairy) $\times$ hp & 0.2 \\
(mean temperature $\left.-9.6^{\circ} \mathrm{C}\right)$ & 1.1 \\
Month (Dec) & 0.3 \\
Month (Nov) & 1.0 \\
Month (Feb) $\times$ breed type (nondairy) & 0.7 \\
Month (Oct) $\times$ breed type (nondairy) & 0.6 \\
Month (Jan) $\times$ sex (male) & 0.6 \\
Month (Nov) $\times$ breed type (nondairy) & -0.4 \\
Month (Aug) $\times$ sex (male) & \\
\hline
\end{tabular}

using an estimate of $£ 310$ per calf death (Kossaibati and Esslemont, 1997) as well as having obvious welfare implications. The effect of environmental conditions on calf mortality rates in GB should certainly be the subject of future research.

Higher neonatal mortality rates in males compared with females has been previously reported (Raboisson et al., 2013; Pannwitz, 2015; Cuttance et al., 2017), potentially related to the higher mortality associated with concomitant dystocia (Johanson et al., 2011), particularly for breeds with heavier birth weights (Gundelach et al., 2009; Linden et al., 2009). Male dairy calves are also often regarded as less economically valuable than heifer calves, and thus may not receive the same standard of care (Renaud et al., 2017), potentially resulting in higher morbidity and mortality rates. Variations in neonatal mortality rates between breed types has previously been reported and is possibly due to management of the breeds rather than the breed itself (Raboisson et al., 2013). Whereas mortality risk might be hypothesized to be higher in beef crossed calves due to increased dystocia (Raboisson et al., 2013), this study suggests that dairy animals are at increased risk of mortality. This has been previously reported in a study of 1.3 million Slovenian calves reporting a 2- to 30 -d mortality rate of $2.68 \%$, and indicating calves from Holstein Friesian dams having higher mortality rates than calves from other breeds, with herd size and calving season also being important factors influencing mortality rate (Voljč et al., 2017). Results from the current study suggest there is an urgent need for addi- 
tional research to identify strategies to reduce mortality rates in male dairy calves in particular.

The increasing trend of calves being sent for slaughter by 3 mo of age has not been previously reported in $\mathrm{GB}$, and while it is not possible to identify reasons for this increase in this study, it is likely that a range of social and economic factors are involved. An increase in the number of male dairy calves entering the beef chain rose by $59 \%$ from 2006 to 2015 , and recent estimates indicate $81 \%$ of all male dairy calves in 2015 were reared for beef in GB (CHAWG, 2018a). The fate of male dairy calves is an important issue for the industry (Renaud et al., 2018), and the increase in male dairy calves entering the beef chain may, in part, be due to this increased rate of early slaughter. There is a slight reduction in on farm mortality of male dairy calves at 0 to 3 mo of age; however, this may also be due to the increased rate of early slaughter of male dairy calves.

Previous on-farm mortality estimates for GB calves are relatively sparse, with previous estimates from national cattle tracing system data suggesting an on-farm 0- to 6-mo mortality rate of $2.47 \%$ for beef and $7.42 \%$ for dairy calves born in 2007 (Gates, 2013), compared with 4.15 and $8.31 \%$ 0- to 6 -mo mortality rates found in the current study for beef and dairy, respectively. Research from 11 farms in the south-east of England in 2011-2012 estimated 24-h, 2-mo dairy calf mortality at $4.5 \%$ (Johnson et al., 2017), similar to the current study's finding of a $4.87 \%$ mortality rate between 0 and 2 mo. Mortality rates have been reported to be highly variable between herds (Brickell et al., 2009), with a recent study reporting a 2- to 56-d mortality rate of $12.7 \%$ for one dairy herd (Mahendran et al., 2017). Mortality rates in GB do not appear to have altered dramatically over time, with historic mortality rates up to $6 \mathrm{mo}$, estimated at around $5.2 \%$ in 1952 (Withers, 1952), extremely similar to the current study reporting $5.5 \%$.

Previous research suggests a significant portion of on farm mortality occurs within early life, with the majority of calves dying within the first month (Gates, 2013; Santman-Berends et al., 2014), and around two-thirds of cattle mortality being within the first 4 mo (Struchen et al., 2015). Several factors affect calf mortality rates up to 3 mo of age (Windeyer et al., 2014), which are largely beyond the scope of this article; however, neonatal diarrhea and pneumonia are likely to play a significant role (Compton et al., 2017).

Although calf mortality is a commonly reported metric in many countries, a wide variety of metrics are being reported, and recent research has evaluated and assessed 10 definitions for calf mortality (SantmanBerends et al., 2019). Age classes for mortality studies also differ considerably between studies (Raboisson et al., 2013), making comparisons challenging. A systematic review and meta-analysis, however, found the rate of perinatal (defined as 0 to $2 \mathrm{~d}$ of age) mortality ranged from 3 to $9 \%$, and was increasing over time, with neonatal (defined as 1-d weaning) mortality ranging from 5 to $11 \%$, which was not found to have changed over time (Compton et al., 2017).

As previously reported, using BCMS databases for research purposes has several limitations (Gates, 2013), particularly the potential exclusion of stillborn calves and early mortality before tagging. Previous estimates suggest around $7.9 \%$ of dairy calves die before $24 \mathrm{~h}$ of age (Brickell et al., 2009), and therefore the current studies estimates of mortality are likely to exclude perinatal mortality. Despite the legal requirement to register all deaths, including those before the registration and tagging of calves, there is a small risk that not all deaths/euthanasias that occur before tagging and registration are recorded. The absence of individual farm and calf level information available for this study meant some assumptions had to be made to calculate mortality figures, particularly that births and deaths were evenly distributed throughout months. Although this is important to recognize, the effects of these potential errors are likely to be small due to the large scale of the data and are unlikely to have significant bearing on the interpretation of the data. Quality of cattle tracing system data has been reported to have improved over time (Green and Kao, 2007) and although it is unlikely to be completely free of error (Gates, 2014), the large scale of data being collected means extremely useful insights can be made.

\section{CONCLUSIONS}

The GB national cattle register provides an important resource in identifying neonatal mortality trends in the GB herd and will provide invaluable insights to the cattle industry if reported on a regular basis. Environmental conditions appear to play a significant role in calf mortality rates, and further research is needed to explore precise environmental factors likely to reduce calf mortality rates in GB.

\section{ACKNOWLEDGMENTS}

This research was carried out as part of a wider calf health research project funded by the Agricultural and Horticulture Development Board (AHDB; Warwickshire, UK), the AgriFood Charities Partnership (Bedford, UK), and the University of Nottingham School of Veterinary Medicine and Science (Leicestershire, UK). There are no conflicts of interest. 


\section{REFERENCES}

Boulton, A. C., J. Rushton, and D. C. Wathes. 2017. An empirical analysis of the cost of rearing dairy heifers from birth to first calving and the time taken to repay these costs. Animal 11:1372-1380. https://doi.org/10.1017/S1751731117000064.

Brickell, J. S., M. M. McGowan, D. U. Pfeiffer, and D. C. Wathes. 2009. Mortality in Holstein-Friesian calves and replacement heifers, in relation to body weight and IGF-I concentration, on 19 farms in England. Animal 3:1175-1182. https://doi.org/10.1017/ S175173110900456X.

CHAWG. 2017. GB Dairy Cattle Welfare Strategy. Accessed Sep. 27, 2019. http://beefandlamb.ahdb.org.uk/wp-content/uploads/2018/ 01/Dairy-Welfare-2017-Web.pdf.

CHAWG. 2018a. Cattle Health and Welfare Group, Dairy Bull Calves. Accessed Jul. 8, 2019. http://beefandlamb.ahdb.org.uk/wp -content/uploads/2018/03/CHAWG-update-on-Dairy-bull-calves -March-2018.pdf.

CHAWG. 2018b. GB Cattle Health and Welfare Group. Accessed Sep. 27, 2019. http://beefandlamb.ahdb.org.uk/wp-content/uploads/ 2018/10/CHAWG-Fourth-Report-2018.pdf.

Compton, C. W. R., C. Heuer, P. T. Thomsen, T. E. Carpenter, C. V. C. Phyn, and S. McDougall. 2017. Invited review: A systematic literature review and meta-analysis of mortality and culling in dairy cattle. J. Dairy Sci. 100:1-16. https://doi.org/10.3168/jds .2016-11302.

Cuttance, E. L., W. A. Mason, R. A. Laven, and C. V. C. Phyn. 2018. The relationship between failure of passive transfer and mortality, farmer-recorded animal health events and body weights of calves from birth until 12 months of age on pasture-based, seasonal calving dairy farms in New Zealand. Vet. J. 236:4-11. https://doi.org/ 10.1016/j.tvjl.2018.04.005.

Cuttance, E. L., W. A. Mason, J. McDermott, R. A. Laven, S. McDougall, and C. V. C. Phyn. 2017. Calf and replacement heifer mortality from birth until weaning in pasture-based dairy herds in New Zealand. J. Dairy Sci. 100:8347-8357. https://doi.org/10 $.3168 /$ jds.2017-12793.

DEFRA. 2018. Department for Environment, Food and Rural Affairs Department of Agriculture, Environment and Rural Affairs (Northern Ireland) The Scottish Government, Rural and Environment Science and Analytical Services. Accessed Oct. 23, 2018. https: //assets.publishing.service.gov.uk/government/uploads/system/ uploads/attachment_data/file/741062/AUK-2017-18sep18.pdf.

Dohoo, I. R., W. Martin, and H. E. Stryhn. 2003. Veterinary Epidemiologic Research. University of Prince Edward Island, Charlottetown, PEI, Canada.

Friedman, J. H. 1991. Multivariate adaptive regression splines. Ann. Statist. 19:1-67. https://doi.org/10.1214/aos/1176347963.

Gabler, M. T., P. R. Tozer, and A. J. Heinrichs. 2000. Development of a cost analysis spreadsheet for calculating the costs to raise a replacement dairy heifer. J. Dairy Sci. 83:1104-1109. https://doi .org/10.3168/jds.S0022-0302(00)74975-7.

Gates, M. C. 2013. Evaluating the reproductive performance of British beef and dairy herds using national cattle movement records. Vet. Rec. 173:499. https://doi.org/10.1136/vr.101488.

Gates, M. C. 2014. Characteristics of replacement breeding cattle trade in Great Britain. Vet. Rec. 175:67. https://doi.org/10.1136/ VR.102351.

Godden, S. 2008. Colostrum management for dairy calves. Vet. Clin. North Am. Food Anim. Pract. 24:19-39. https://doi.org/10.1016/ J.CVFA.2007.10.005.

Green, D. M., and R. R. Kao. 2007. Data quality of the cattle tracing system in Great Britain. Vet. Rec. 161:439-443. https://doi.org/ 10.1136/VR.161.13.439.

Gundelach, Y., K. Essmeyer, M. K. Teltscher, and M. Hoedemaker. 2009. Risk factors for perinatal mortality in dairy cattle: Cow and foetal factors, calving process. Theriogenology 71:901-909. https:/ /doi.org/10.1016/j.theriogenology.2008.10.011.

Hultgren, J., and C. Svensson. 2009. Heifer rearing conditions affect length of productive life in Swedish dairy cows. Prev. Vet. Med. 89:255-264. https://doi.org/10.1016/j.prevetmed.2009.02.012.
Johanson, J. M., P. J. Berger, S. Tsuruta, and I. Misztal. 2011. A Bayesian threshold-linear model evaluation of perinatal mortality, dystocia, birth weight, and gestation length in a Holstein herd. J. Dairy Sci. 94:450-460. https://doi.org/10.3168/jds.2009-2992.

Johnson, K. F., N. Chancellor, C. C. Burn, and D. C. Wathes. 2017. Prospective cohort study to assess rates of contagious disease in pre-weaned UK dairy heifers: Management practices, passive transfer of immunity and associated calf health. Vet. Re. Open 4:e000226. https://doi.org/10.1136/vetreco-2017-000226.

Kossaibati, M. A., and R. J. Esslemont. 1997. The costs of production diseases in dairy herds in England. Vet. J. 154:41-51. https://doi .org/10.1016/S1090-0233(05)80007-3.

Kuhn, M. 2018. caret: Classification and Regression Training', R package. https://github.com/topepo/caret/.

Linden, T. C., R. C. Bicalho, and D. V. Nydam. 2009. Calf birth weight and its association with calf and cow survivability, disease incidence, reproductive performance, and milk production. J. Dairy Sci. 92:2580-2588. https://doi.org/10.3168/jds.2008-1603.

Lombard, J. E., F. B. Garry, S. M. Tomlinson, and L. P. Garber. 2007. Impacts of dystocia on health and survival of dairy calves. J. Dairy Sci. 90:1751-1760. https://doi.org/10.3168/jds.2006-295.

Mahendran, S. A., R. Booth, L. Beekhuis, A. Manning, T. Blackmo, A. Vanhoudt, and N. Bell. 2017. Assessing the effects of weekly preweaning health scores on dairy calf mortality and productivity parameters: Cohort study. Vet. Rec. 181:196-201. https://doi.org/ $10.1136 / v r .104197$

Milborrow, S. 2019. Earth Package. Derived from mda:mars by Trevor Hastie and Rob Tibshirani. Uses Alan Miller's Fortran utilities with Thomas Lumley's leaps wrapper. Accessed Jan. 2, 2020. https://cran.r-project.org/web/packages/earth/earth.pdf.

Mõtus, K., K. Reimus, T. Orro, A. Viltrop, and U. Emanuelson. 2017. On-farm mortality, causes and risk factors in Estonian beef cowcalf herds. Prev. Vet. Med. 139(Pt A):10-19. https://doi.org/10 .1016/j.prevetmed.2016.10.014.

Olson, D. P., C. J. Papasian, and R. C. Ritter. 1980. The effects of cold stress on neonatal calves. II. Absorption of colostral immunoglobulins. Can. J. Comp. Med. 44:19-23.

Ortiz-Pelaez, A., D. G. Pritchard, D. U. Pfeiffer, E. Jones, P. Honeyman, and J. J. Mawdsley. 2008. Calf mortality as a welfare indicator on British cattle farms. Vet. J. 176:177-181. https://doi.org/ 10.1016/J.TVJL.2007.02.006.

Pannwitz, G. 2015. Standardized analysis of German cattle mortality using national register data. Prev. Vet. Med. 118:260-270. https:/ /doi.org/10.1016/j.prevetmed.2014.11.020.

Raboisson, D., F. Delor, E. Cahuzac, C. Gendre, P. Sans, and G. Allaire. 2013. Perinatal, neonatal, and rearing period mortality of dairy calves and replacement heifers in France. J. Dairy Sci. 96:2913-2924. https://doi.org/10.3168/jds.2012-6010.

R Core Team. 2018. R: A Language and Environment for Statistical Computing. https://www.r-project.org/.

Renaud, D. L., T. F. Duffield, S. J. LeBlanc, D. B. Haley, and D. F. Kelton. 2017. Management practices for male calves on Canadian dairy farms. J. Dairy Sci. 100:6862-6871. https://doi.org/10.3168/ jds.2017-12750.

Renaud, D. L., D. F. Kelton, S. J. LeBlanc, D. B. Haley, and T. F. Duffield. 2018. Calf management risk factors on dairy farms associated with male calf mortality on veal farms. J. Dairy Sci. 101:1785-1794. https://doi.org/10.3168/jds.2017-13578.

Robison, J. D., G. H. Stott, and S. K. DeNise. 1988. Effects of passive immunity on growth and survival in the dairy heifer. J. Dairy Sci. 71:1283-1287. https://doi.org/10.3168/jds.S0022-0302(88)79684 $-8$.

Santman-Berends, I. M., Y. Schukken, and G. van Schaik. 2019. Quantifying calf mortality on dairy farms: Challenges and solutions. J. Dairy Sci. 102:6404-6417. https://doi.org/10.3168/jds.2019-16381.

Santman-Berends, I. M., M. Buddiger, A. J. Smolenaars, C. D. Steuten, C. A. Roos, A. J. Van Erp, and G. Van Schaik. 2014. A multidisciplinary approach to determine factors associated with calf rearing practices and calf mortality in dairy herds. Prev. Vet. Med. 117:375-387. https://doi.org/10.1016/j.prevetmed.2014.07.011. 
Struchen, R., M. Reist, J. Zinsstag, and F. Vial. 2015. Investigating the potential of reported cattle mortality data in Switzerland for syndromic surveillance. Prev. Vet. Med. 121:1-7. https://doi.org/ 10.1016/j.prevetmed.2015.04.012.

UK Government. 2014. Cattle identification inspections: What to expect - GOV.UK. Accessed Sep. 27, 2019. https://www.gov.uk/ guidance/cattle-identification-inspections-what-to-expect.

UK Government. 2018. Livestock numbers in England and the UK. Accessed Jan. 2, 2020. https://www.gov.uk/government/statistical -data-sets/structure-of-the-livestock-industry-in-england-at -december.

Veldhuis, A., H. Brouwer-Middelesch, A. Marceau, A. Madouasse, Y. Van der Stede, C. Fourichon, S. Welby, P. Wever, and G. van Schaik. 2016. Application of syndromic surveillance on routinely collected cattle reproduction and milk production data for the early detection of outbreaks of Bluetongue and Schmallenberg viruses. Prev. Vet. Med. 124:15-24. https://doi.org/10.1016/j prevetmed.2015.12.006.

Voljč, M., M. Čepon, S. Malovrh, and S. Žgur. 2017. The Effect of dam breed on calf mortality in the first month of life in Slovenia, Agriculturae Conspectus Scientificus. Faculty of Agriculture, University of Zagreb. Accessed Jun. 18, 2019. https://hrcak.srce.hr/ index.php?show $=$ clanak\&id_clanak_jezik $=282839$. von Keyserlingk, M. A. G., J. Rushen, A. M. de Passillé, and D. M. Weary. 2009. Invited review: The welfare of dairy cattle-Key concepts and the role of science. J. Dairy Sci. 92:4101-4111. https:// doi.org/10.3168/jds.2009-2326.

Windeyer, M. C., K. E. Leslie, S. M. Godden, D. C. Hodgins, K. D. Lissemore, and S. J. LeBlanc. 2014. Factors associated with morbidity, mortality, and growth of dairy heifer calves up to 3 months of age. Prev. Vet. Med. 113:231-240. https://doi.org/10.1016/j .prevetmed.2013.10.019.

Withers, F. W. 1952. Mortality rates and disease incidence in calves in relation to feeding, management and other environmental factors. Br. Vet. J. 108:382-405. https://doi.org/10.1016/S0007 $-1935(17) 51348-2$

\section{ORCIDS}

Robert M. Hyde (ㄴ) https://orcid.org/0000-0002-8705-9405 Martin J. Green () https://orcid.org/0000-0002-6408-6443 Chris Hudson @ https://orcid.org/0000-0003-4777-062X

Jenny Gibbons $\odot$ https://orcid.org/0000-0001-7719-1587

Peter M. Down ๑ https://orcid.org/0000-0003-1896-7255 